\title{
The contemporary design: leaning the mindset through technology
}

\section{Opinion}

Design is not an unfamiliar word for most of us rather it is a routine existence in our daily life. At one side, it is deliberately used to describe things in relation to its true meaning on the other hand this nomenclature merely has a place in conversation without the representation of its true meaning. In either way, its importance in our lives as a tangible thing as a concept. Since ancient times, the design is involved and influences human life either directly or indirectly as a functional tool of existence, comfort, and progression. The mindset of realization about learning and mastering the particular aspect of design is the only way to transform into a better future that can change the lives of individuals. It started as a tool of necessity but with the passage of time it has become a professional discipline engulfing almost everything that we breathe and live around. From fashion to product design, from textiles to interior and graphic design the concept of giving an identity to environment has emerged rapidly.

The origins of design studies can be traced down to the history where the field actually started and then became a widely studied academic discipline with larger themes. ${ }^{1}$ The design study includes rainbow of sub-categories that serve as professional platforms for individuals to work in and serve the communities. The design studies in academia are based on certain principals and elements that make it an integral part of generic design. It is the method of studies that train the minds to think and operate in a sequential manner not leaving a single hook untied. The design process is based on steps that have their individual importance and place in a chain of defined methodology. While practicing these methodologies professionally will ensure the quality of designed resultants. The query here is what leads to research which is the starting phase of learning and mastering design as a process and all its tangible outcomes. Technology revolution over the years has its own impact on different sectors of professionalism; design being no exception got benefited as well soaring to new heights of creativity and functionality. The learning experiences of academic environment also face the challenges of keeping a balance between technology and design as a separate identity.

The ease of the design processes via the help of technology especially in the academic arena that has made the contemporary mind to deviate and skip one of the most depended processes of research and thus has restricted brainstorming possibilities. It seems like technology at some point in time affects the process of creativity in offering short cut to solutions that otherwise demands attention and research in depth.

Computer technology has offered much time saving easier solutions to designers, but somewhere along the line its precision of design process has killed the touch and feel of artist's design. A good example is the introduction of CAD (computer aided design) which
Volume 3 Issue 5 - 2017

\author{
Mudassar Abbas, Adil Masood Qazi \\ School of Textile and Design, University of Management and \\ Technology, Pakistan
}

Correspondence: Mudassar Abbas, School of Textile and Design, University of Management and Technology, C-II Johar Town Lahore 54770, Pakistan, Tel 00923214100626, Email mudassirabbas@yahoo.com

Received: December 21, 2017| Published: December 27, 2017

has made the task of the designers easier and has enabled them to represent their imaginations in a visual language, but at the same time damaged the design process and creative approach of exploration of ideas both in raw and finished form.

The use of technology has also saturated the design process and the resultant products. In present times exploring of possibilities without the technical assistance seems inevitable. The contemporary mindset shifts now towards blending technology and design in many disciplines, they are constantly hunting the possibilities that relay on technology for their design process to take shape and not just the design itself.

The learning experience of contemporary academic environment also faces the challenges of keeping a balance between technology and design as separate identities and also a smart blend of the two. A serious effort must be initiated to define the pure design process where every step must display its existence and importance, starting with the solid foundation laid upon research. It must be made aware that technology is just a tool to complete the bigger picture of design and not a process of design.

\section{Acknowledgements}

None.

\section{Conflict of interest}

Author declares there is no conflict of interest in publishing the article.

\section{References}

1. Buchanan Richard. Design Research and the New Learning. Design Issues. $2001 ; 17(4): 3-23$. 